\title{
Histopathological effect of co-administration of efavirenz and vitamin $E$ on the liver, and biochemical parameters in wistar rats
}

\author{
Aniekan I Peter ${ }^{1}$, Inocent A Edagha ${ }^{2}$ \\ ${ }^{1}$ Senior Lecturer, ${ }^{2}$ Lecturer, Department of Anatomy, College of Health Sciences, University of Uyo, \\ PMB 1017, Uyo, Nigeria
}

Background: Efavirenz is a drug used singly and in combination as highly active antiretroviral therapy (HAART) used for the treatment of human immunodeficiency virus (HIV). Aims and Objectives: To investigate the effects of Efavirenz and vitamin $E$ on the histopathology and biochemical parameters in the liver of Wistar rats. Materials and Methods: Twenty five Wistar rats were divided into five groups. Group A were administered with $1 \mathrm{ml}$ of distil water; group B animals were administered with $8.57 \mathrm{mg} / \mathrm{kg}$ of Efavirenz, group C were administered with $17.14 \mathrm{mg} / \mathrm{kg}$ Efavirenz; group D were administered with $8.57 \mathrm{mg} / \mathrm{kg}$ of Efavirenz and $14.82 \mathrm{mg} / \mathrm{kg}$ Vitamin E, and group E were administered with $14.82 \mathrm{mg} / \mathrm{kg}$ of Vitamin $E$ for 32 days. On day 33, the rats were sacrificed using chloroform inhalation method. The liver were excised, routinely processed, stained using haematoxylin and eosin method, and viewed in DPX medium under light microscope. Blood samples from the rats were collected and then centrifuged after 30 minutes to obtain the serum for analysis of aspartate amino transaminase (AST), alanine amino transaminase (ALT), alkaline phosphatase (ALP), and total bilirubin (TB). Results: The liver of Wistar rats administered with Efavirenz, showed distortions with various degree of vacoulations, dilatation of sinusoidal spaces and nuclei pyknoctic changes. In the group where Efavirenz was combined with vitamen $E$ this changes were ameliorated. This also agreed with the biochemical changes which showed significant levels of increase in AST and ALT in Efavirenz groups, this changes were also ameliorated in the group that Efavirenz was combined with vitamin E. Conclusion: Efavirenz administration can damage the liver, vitamin E can ameliorate this effect, therefore Vitamin E should be prescribed for patients on Efavirenz administration.

Key words: Histopathological, Efavirenz, Liver, Vitamin E, Biochemical parameters
Access this article online

Website:

http://nepjol.info/index.php/AJMS

DOI: 10.3126/ajms.v7i5.13542

E-ISSN: 2091-0576

P-ISSN: 2467-9100

\section{INTRODUCTION}

The NNRTI Efavirenz is an important component of the treatment of HIV infection for many years and has contributed significantly to the evolution of HAART. Currently Efavirenz is a recommended option for initial therapy and is usually regarded as the preferred NNRTI. ${ }^{1-4}$ Indeed, the combination of Efavirenz plus two NRTIs is recommended as the regimen of choice for initial therapy in the current UK guidelines. ${ }^{1}$ Peak Efavirenz plasma concentrations are reached by $5 \mathrm{~h}$ following single oral doses in uninfected volunteers. ${ }^{5}$ The time to peak plasma concentrations is $\sim 3-5 \mathrm{~h}$ and steadystate plasma concentrations of efavirenz are reached in 6-7 days. ${ }^{5}$ The bioavailability of a single $600 \mathrm{mg}$ dose of Efavirenz hard capsules in uninfected volunteers is increased by $17 \%-22 \%$ by food. ${ }^{5}$ Efavirenz is highly bound $(\sim 99.5 \%-99.75 \%)$ to human plasma proteins, predominantly albumin. ${ }^{5,6}$

Efavirenz has a long half life of $52 \mathrm{~h}$ after single doses, and $55 \mathrm{~h}$ after multiple doses. ${ }^{5}$ The long half-life of Efavirenz makes it suitable for once-daily dosing. The recommended dosage in adults is $600 \mathrm{mg}$ once daily. Many 
studies comparing different NRTI combinations have used Efavirenz as the common third agent. ${ }^{7-11}$

Adherence is a major predictor of the success of HAART, ${ }^{12,13}$ with higher adherence rates leading to a lower risk of viral rebound and resistance development. ${ }^{14}$ The complexity of the treatment regimen is an important barrier to good adherence ${ }^{13,15}$ and patients generally prefer the simplicity of once-daily regimens. ${ }^{16,17}$ The use of once-daily agents and the co-formulation of multiple anti-retrovirals in fixed-dose combinations have simplified HAART regimens in recent years. As well as providing simplified initial HAART regimens, these approaches have been used in switch strategies to improve convenience for patients stabilized on more complicated regimens.

Efavirenz has been generally well tolerated in clinical trials. According to the systematic review by Bartlett et al. $4 \%-16 \%$ of patients treated with Efavirenz plus two NRTIs discontinued treatment due to adverse events, ${ }^{18}$ the NRTI combinations of Lamivudine plus Zidovudine or Abacavir were associated with the higher discontinuation rate.

The most notable adverse events associated with Efavirenz are rash and central nervous system (CNS) symptoms. Rash is common, but led to discontinuation in $<2 \%$ of patients and was severe in $<1 \% .{ }^{19}$ When Efavirenz and Nevirapine were directly compared (each plus Lamivudine and Stavudine) discontinuations due to adverse events or HIV events occurred in $15.8 \%$ of patients treated with efavirenz and $24.1 \%$ of patients treated with nevirapine once daily. ${ }^{20}$ The difference between the groups in adverse event-related discontinuations was mainly due to a greater incidence of rash and hepatobiliary toxicity with Nevirapine. ${ }^{20}$

CNS or neuropsychiatric disturbances have been reported in $\sim 25 \%-70 \%$ of patients receiving Efavirenz. ${ }^{21-25}$ Symptoms include dizziness, headache, confusion, impaired concentration, agitation, amnesia, psychotic symptoms, sleep abnormalities, abnormal dreams and insomnia. These symptoms usually arise within the first few days of treatment and lead to early discontinuation of Efavirenz in $\sim 4 \%-10 \%$ of patients, although some investigators have reported higher discontinuation rates. ${ }^{26}$ The prevalence of most neuropsychiatric symptoms declines within a few weeks if therapy is continued. ${ }^{21,22,24,25,27}$

Studies in animals have suggested that the effects of Efavirenz on cytokines may play a role in depression associated with Efavirenz. ${ }^{27}$ Sleep disturbances may play a role in the development of neuropsychiatric symptoms. ${ }^{26}$

While exposure to HAART increases the risk of myocardial infarction, ${ }^{28}$ this appears to be due to PIs and not to
NNRTIs ${ }^{29}$ Renal toxicity has been reported, albeit rarely, with Tenofovir administration. ${ }^{30}$ Although small differences in glomerular filtration rate have occurred over time when Tenofovir was combined with Efavirenz over 144 weeks in HAART-naive patients, no clinically relevant renal disease or adverse events were observed. ${ }^{31}$ Approximately $75 \%$ of the idiosyncratic drug reactions result in liver injury or death. ${ }^{32}$ Drug-induced hepatic injury is the most common reason cited for withdrawal of an approved drug. Physicians must be vigilant in identifying drugrelated liver injury because early detection can decrease the severity of hepatotoxicity if the drug is discontinued. The manifestations of drug-induced hepatotoxicity are highly variable, ranging from asymptomatic elevation of liver enzymes to fulminant hepatic failure. ${ }^{32}$ The objective of this study was to investigate the effects of combined administration of Efavirenz and vitamin $\mathrm{E}$ on the histopathology and biochemical parameters in the liver of Wistar rats.

\section{MATERIALS AND METHODS}

Twenty five Wistar rats weighing between $140 \mathrm{~g}-192 \mathrm{~g}$ were used for the study. The rats were divided into five groups. Control (group) A were administered with $1 \mathrm{ml}$ of distil water; group B were administered with $8.57 \mathrm{mg} / \mathrm{kg}$ body weight of Efavirenz; group $C$ were administered with Double dose of $17.14 \mathrm{mg} / \mathrm{kg}$ body weight of Efavirenz; group D were administered with $8.57 \mathrm{mg} / \mathrm{kg}$ body weight of Efavirenz and $14.82 \mathrm{mg} / \mathrm{kg}$ body weight of Vitamin E; and group E were administered with $14.82 \mathrm{mg} / \mathrm{kg}$ body weight of Vitamin E. Drug administration lasted for 32 days. The animals were handled according to the guidelines for the treatment of laboratory animals. On day 33 the rats were sacrificed using chloroform inhalation method. The liver were excised, routinely processed, stained using haematoxylin and eosin method, and viewed in DPX medium under light microscope. Blood samples from each rat were collected using syringes and needles and separated into sample bottles and allowed to stand for 30 minutes for clotting to take place and then centrifuged. The serum extracted into fresh test tubes and stored in a refrigerator for analysis of aspartate amino transaminase test (AST), alanine amino transaminase test (ALT), alkaline phosphotase (ALP) and total bilirubin (TB).

\section{Measurement of alkaline phosphatase}

This was by the optimized standard method recommended by the deutsche Geseiischage fur Klinishche Chemic GSCC (1972). P-nitrophenyl phosphate is hydrolysed to phosphate and p-nitrophenol in the presence of ALP. A calculated amount of sample $0.01 \mathrm{ml}$ in a test tube was mixed with reagent $(0.5 \mathrm{ml})$ containing the substrate $\mathrm{p}$-nitrophenyl 
phosphate and brought to room temperature. The solution was mixed, initial absorbance read after 1 minute. The reaction was allowed to stand for 3 minutes and the absorbance read again at $405 \mathrm{~nm}$. Alkaline phosphates activity was calculated from.

$$
\begin{aligned}
\mathrm{UL} & =2760 \times \Delta \mathrm{A} \mathrm{nm} / \text { minute micro } \\
\mathrm{UL} & =\text { Unit of Alkaline Phosphatase affinity } \\
\Delta \mathrm{A} & =\text { Change in absorbance }
\end{aligned}
$$

Measurement of alanine and aspartate transferase The measurement of ALT and AST activities in the serum were done using endpoint colorimetric-diagnostic kit (Randox; Labouratories UK) based on Reitman and Frankel $(1952)^{10}$ method. ${ }^{9,10}$ The pyruvate produced by transamination reaction between L-alanine and ketoglutarate reacts with 2, 4, dinitrophenyl hydrazine to give a colored hydrazone, which represents alanine aminotransferase activity. The oxaloacetate hydrazone formed with 2, 4 dinitrophenyl hydrazine is used to measure aspartate amino transfarase (AST). Both AST and ALT were read at $540 \mathrm{~nm}$ wavelength.

All results were analyzed using one way Analysis of Variance (ANOVA) and post hoc test values.

\section{RESULT}

Group A: Photomicrograph of the histology of the liver administered with distilled water. Showing normal liver architecture; the central vein $(\mathrm{V})$, hepatocytes plates $(\mathrm{H})$, sinusoidal spaces $(\mathrm{S})$ and nuclei $(\mathrm{N})$ are all normal $\mathrm{H} \& \mathrm{E}$, $\times 100$ and $X 400$ as shown in Figure 1 .

Group B: Photomicrograph of the histology of the liver administered with $8.57 \mathrm{mg} / \mathrm{kg}$ body weight of Efavirenz showing moderate distortion of liver cellular architecture; the central vein $(\mathrm{V})$ are dilated, hepatocytes plates $(\mathrm{H})$ are swollen, sinusoidal spaces (S) dilation and pyknotic nuclei (N) H \& E, $\times 100$ and x 400 as shown in Figure 2.

Group C: Photomicrograph of the histology of the liver administered with double dose $17.14 \mathrm{mg} / \mathrm{kg}$ body weight of Efavirenz; showing severe distortion of liver cellular architecture; the central vein (V) are dilated, hepatocytes plates $(\mathrm{H})$ are swollen, sinusoidal spaces $(\mathrm{S})$ dilation, pyknotic nuclei $(\mathrm{N})$ and karyorrhexis $\mathrm{H} \& \mathrm{E}, \times 100$ and $\mathrm{x}$ 400 as shown in Figure 3.

Group D: Photomicrograph of the histology of the liver administered with $8.57 \mathrm{mg} / \mathrm{kg}$ body weight of Efavirenz and $14.82 \mathrm{mg} / \mathrm{kg}$ body weight of Vitamin E showing mild

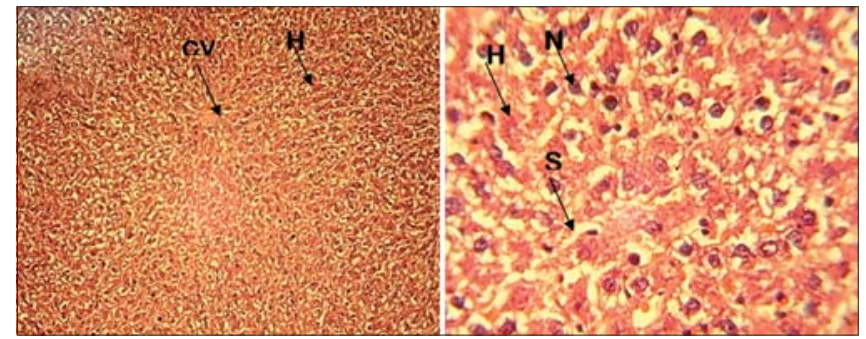

Figure 1: Photomicrograph of Group A administered with distil water. $H \& E X 100 \times 400$

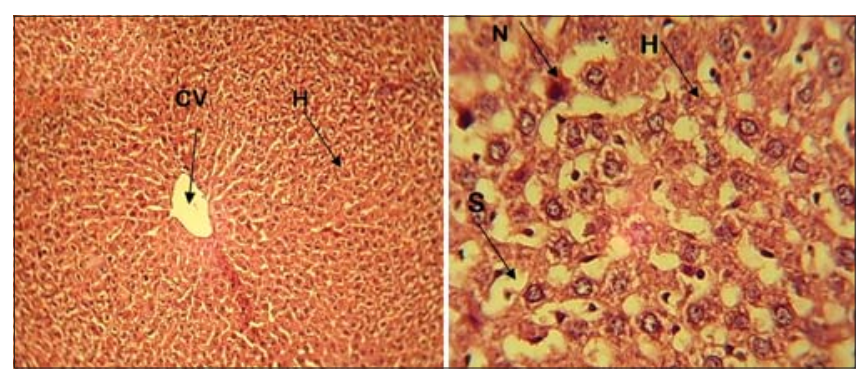

Figure 2: Photomicrograph of Group B administered with 8.57 mg/kg body weight of Efavirenz. H\& E X 100 X400
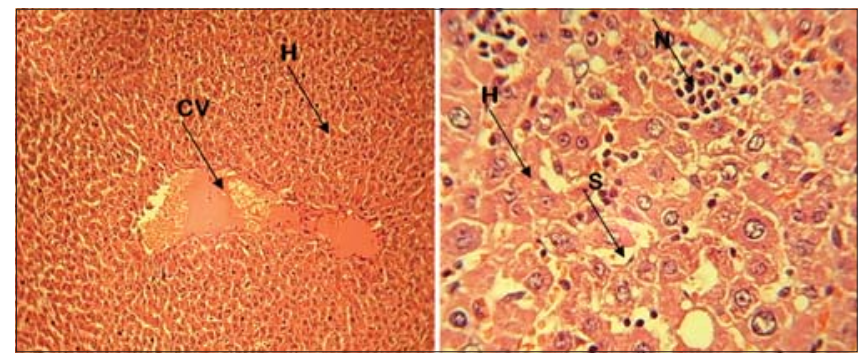

Figure 3: Photomicrograph of Group $C$ administered with double dose $17.14 \mathrm{mg} / \mathrm{kg}$ body weight of Efavirenz. H\& E X 100 X400

distortion of liver cellular architecture; the central vein (V) are normal, sinusoidal spaces (S) are dilated with normal nucleus $(\mathrm{N})$ when compared with the control group $\mathrm{A}$. $\mathrm{H} \& \mathrm{E}, \times 100$ as shown in Figure 4.

Group E: Photomicrograph of the histology of the liver administered with $14.82 \mathrm{mg} / \mathrm{kg}$ body weight of Vitamin E. Showing normal liver architecture; the central vein (V), hepatocytes plates $(H)$, sinusoidal spaces $(S)$ and nuclei (N) are all normal H \& E, $\times 100$ and X 400 as shown in Figure 5.

\section{DISCUSSION}

Drugs are an important cause of liver injury. More than 900 drugs, toxins, and herbs have been reported to cause liver injury, and drugs account for $20-40 \%$ of all instances of fulminant hepatic failure. Knowledge of the commonly implicated agents and a high index of suspicion are essential in diagnosis. ${ }^{32}$ The current study was designed to investigate 


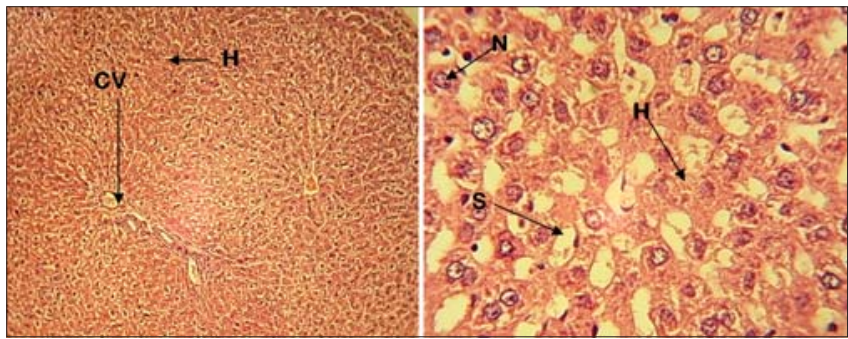

Figure 4: Photomicrograph of Group D administered with $8.57 \mathrm{mg} / \mathrm{kg}$ body weight of Efavirenz and $14.82 \mathrm{mg} / \mathrm{kg}$ body weight of Vitamin $\mathrm{E}$. $H \& E X 100 \times 400$

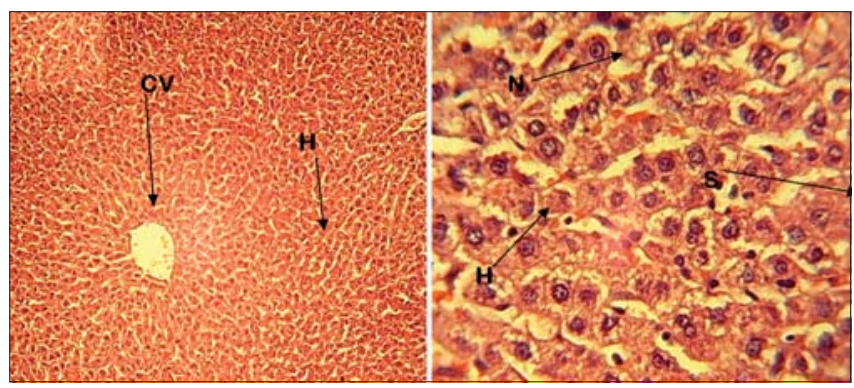

Figure 5: Photomicrograph of Group E administered with $14.82 \mathrm{mg} / \mathrm{kg}$ body weight of Vitamin E. H\& E X 100 X400

Table 1: Levels of AST, ALT and ALP in serum of
Wistar rats
\begin{tabular}{lcccc} 
The level of these biomarkers were expressed as mean \pm SEM \\
\hline Group & AST & ALT & ALP & Total BIL \\
\hline A & $63.00 \pm 3.89$ & $21.50 \pm 1.32$ & $58.25 \pm 1.70$ & $3.35 \pm 0.69$ \\
B & $120.00 \pm 7.60^{*}$ & $34.25 \pm 4.23^{*}$ & $58.75 \pm 1.44$ & $4.45 \pm 1.24$ \\
C & $111.00 \pm 7.52^{*}$ & $33.00 \pm 2.48^{*}$ & $57.80 \pm 2.36$ & $5.73 \pm 1.24$ \\
D & $67.00 \pm 5.58$ & $22.00 \pm 2.35$ & $59.00 \pm 0.71$ & $3.98 \pm 0.69$ \\
E & $87.75 \pm 6.79$ & $24.00 \pm 1.87$ & $55.25 \pm 1.31$ & $3.77 \pm 0.62$ \\
\hline *Significant difference from control group (p<0.05)
\end{tabular}

the effects of Efavirenz and its co-administration with vitamin $\mathrm{E}$. The results obtained from this study revealed that oral administration of Efavirenz had toxic effects on the liver, with moderate to severe distortion of liver cellular architecture; dilatation of the central vein, sinusoidal spaces and pyknotic nuclei changes. This finding is supported by clinical findings that Efavirenz can compromise the liver and renal functions. ${ }^{33,34}$ Other adverse effects includes; insomnia, nightmares, confusion, memory loss, and depression ${ }^{35}$ and more serious symptoms such as psychosis may occur in patients with compromised liver or kidney function. ${ }^{33,34}$ In general, severe hepatic injuries have been documented to occur in HAART patients, regardless of their treatment. ${ }^{36} \mathrm{ALT}$ and AST are liberated into the blood whenever liver cells are damaged and increased plasma enzymes activity is a sensitive index of hepatic damage. ${ }^{37,38}$ Neither of these enzymes is specific to the liver but ALT occurs in much higher concentration in the liver than elsewhere. ${ }^{38}$ Therefore, the increased serum ALT and ALP activity in this study, as shown in table 1 more specifically reflects hepatic damage. ${ }^{37,38}$ This agreed with the histological findings which revealed liver distortions. The changes caused by the administration of Efavirenz were ameliorated by vitamin $\mathrm{E}$ in the group that Efavirenz was combined with vitamin $\mathrm{E}$. This must have been as a result of the antioxidant activity of vitamin $\mathrm{E}$. This was shown both in the histological appearance which only had mild distortions and the liver function test that was not significantly different from control group (Table 1). Folic acid had earlier been reported to prevent neural tube defect. ${ }^{39}$ Another study showed the amelioration of Lamivudine induced toxicity in the histology of cerebellum when co-administered with neurovite. ${ }^{40}$

Drug-related toxicity leads to poor medication adherence and ultimate virological failure. ${ }^{41}$ Hepatic and cerebelar toxicity due to antiretroviral drug was also observed in some studies, ${ }^{42,43}$ This is why studies on adverse drug reactions are very important and relevant, to identify potential risk and prevent of drug toxicity. For HIV treatment it will help to improve compliance and reduce the incidence of drug resistance.

In conclusion, chronic administration of Efavirenz leads to toxic changes in the histology and biochemical indices in the liver of Wistar rats, its combined administration with vitamin $\mathrm{E}$ ameliorated these effects. Therefore Efavirenzshould be given with vitamin $\mathrm{E}$ and strict monitoring of liver function should be a norm in patients taking Efavirenz.

\section{REFERENCES}

1. Gazzard BG. British HIV Association Guidelines for the treatment of HIV-1-infected adults with antiretroviral therapy 2008. HIV Med 2008; 9:563-608.

2. DHHS Panel on Antiretroviral Guidelines for Adults and Adolescents. Guidelines for the Use of Antiretroviral Agents in HIV-1-Infected Adults and Adolescents. 2008:1-146. Cited (31 ${ }^{\text {st }}$ July 31,2015$)$ available fromhttp://aidsinfo.nih.gov/ contentfiles/AdultandAdolescentGL.pdf.

3. Clumeck N, Pozniak A and Raffi F. European AIDS Clinical Society (EACS) guidelines for the clinical management and treatment of HIV-infected adults. HIV Med 2008;9:65-71.

4. Hammer SM, Eron JJ, Reiss P, Schooley RT, Thompson MA, Walmsley S, et al. Antiretroviral treatment of adult HIV infection: 2008 recommendations of the International AIDS Society-USA panel. JAMA 2008; 300: 555-570.

5. Bristol-Myers Squibb Pharmaceuticals Ltd. Efavirenz: Summary of Product Characteristics. European Medicines Evaluation Agency; 2009. cited(July 31, 2015 date last accessed) Available from http://emc.medicines.org.uk/medicine/11284/SPC/ Sustiva+600+mg+Film-Coated+Tablets.

6. Almond LM, Hoggard PG, Edirisinghe D, Khoo SH and Back DJ. Intracellular and plasma pharmacokinetics of efavirenz in HIVinfected individuals. J Antimicrob Chemother 2005; 56:738-744. 
7. Moyle GJ, De Jesus E, Cahn P, Castillo SA, Zhao H, Gordon DN, et al. Abacavir once or twice daily combined with once-daily lamivudine and efavirenz for the treatment of antiretroviralnaive HIV-infected adults: results of the Ziagen Once Daily in Antiretroviral Combination Study. J Acquir Immune Defic Syndr 2005; 38:417-425.

8. DeJesus E, Herrera G, Teofilo E, Gerstoft J, Buendia CB, Branet JD, et al. Abacavir versus zidovudine combined with lamivudine and efavirenz, for the treatment of antiretroviralnaive HIV-infected adults. Clin Infect Dis 2004; 39:1038-1046.

9. Gallant JE, Staszewski S, Pozniak AL, De Jesus E, Suleiman JM, Miller MD, et al. Efficacy and safety of tenofovir DF vs stavudine in combination therapy in antiretroviral-naive patients: a 3-year randomized trial. JAMA 2004; 292:191-201.

10. Saag MS, Cahn P, Raffi F, Wolff M, Pearce D, Molina JM, et al. Efficacy and safety of emtricitabine vs stavudine in combination therapy in antiretroviral-naive patients: a randomized trial. JAMA 2004; 292:180-189.

11. Arribas JR, Pozniak AL, Gallant JE, Dejesus E, Gazzard B, Campo RE, et al. Tenofovir disoproxil fumarate, emtricitabine, and efavirenz compared with zidovudine/lamivudine and efavirenz in treatment-naive patients: 144-week analysis. J Acquir Immune Defic Syndr 2008; 47:74-78.

12. Bangsberg DR. Preventing HIV antiretroviral resistance through better monitoring of treatment adherence. J Infect Dis 2008; 197(Suppl 3):S272-S278.

13. Mills EJ, Nachega JB, Bangsberg DR, Singh S, Rachlis B, Wu P, et al. Adherence to HAART: a systematic review of developed and developing nation patient-reported barriers and facilitators. PLoS Med 2006; 3: e438.

14. Maggiolo F, Airoldi M, Kleinloog HD, Callegaro A, Ravasio V, Arici $C$, et al. Effect of adherence to HAART on virologic outcome and on the selection of resistance-conferring mutations in NNRTI- or PI-treated patients. HIV Clin Trials 2007;8: 282-292.

15. Maggiolo F, Ripamonti D, Arici C, Gregis G, Quinzan G and Camacho GA. Simpler regimens may enhance adherence to antiretrovirals in HIV-infected patients. HIV Clin Trials 2002; 3: $371-378$.

16. Moyle G. The assessing patients' preferred treatments (APPT-1) study. Int J STD AIDS. 2003; 14(Suppl1): 34-36.

17. Claxton AJ, Cramer J and Pierce C. A systematic review of the associations between dose regimens and medication compliance. Clin Ther 2001; 23:1296-1310.

18. Bartlett JA, Chen SS and Quinn JB. Comparative efficacy of nucleoside/nucleotide reverse transcriptase inhibitors in combination with efavirenz: results of a systematic overview. HIV Clin Trials 2007;8:221-226.

19. European Medicines Agency. EPARs for Authorised Medicinal Products for Human Use: Sustiva SmPC. Cited (13 July, 2015) available from http://www.emeauropa.eu/humandocs/Humans/ EPAR/sustiva/sustiva.htm.

20. van Leth F, Phanuphak P, Ruxrungtham K, Baraldi E, Miller S, Gazzard B, et al. Comparison of first-line antiretroviral therapy with regimens including nevirapine, efavirenz, or both drugs, plus stavudine and lamivudine: a randomised open-label trial, the 2NN Study. Lancet 2004; 363:1253-1263.

21. European Medicines Agency. EPARs for Authorised Medicinal Products for Human Use: SustivaSmPC. cited (July, 2015) available from http://www.emea.europa.eu/humandocs/ Humans/EPAR/sustiva/sustiva.htm.

22. Fumaz CR, Tuldra A, Ferrer MJ, Paredes R, Bonjoch A, Jou T, et al. Quality of life, emotional status, and adherence of HIV1-infected patients treated with efavirenz versus protease inhibitor-containing regimens. J Acquir Immune Defic Syndr 2002;29:244-253.
23. Hawkins T, Geist C, Young B, Giblin A, Mercier RC, Thornton K, et al. Comparison of neuropsychiatric side effects in an observational cohort of efavirenz- and protease inhibitor-treated patients. HIV Clin Trialsc2005;c6:187-196.

24. Staszewski S, Morales-Ramirez J, Tashima KT, Rachlis A, Skiest D, Stanford J, et al. Efavirenz plus zidovudine and lamivudine, efavirenz plus indinavir, and indinavir plus zidovudine and lamivudine in the treatment of HIV-1 infection in adults. N Engl J Med 1999; 341:1865-1873.

25. Perez-Molina JA. Safety and tolerance of efavirenz in different antiretroviral regimens: results from a national multicenter prospective study in 1,033 HIV-infected patients. HIV Clin Trials 2002; 3:279-286.

26. Munoz-Moreno JA, Fumaz CR, Ferrer MJ, González-García M, Moltó J, Negredo E, et al. Neuropsychiatric symptoms associated with efavirenz: prevalence, correlates, management. A neurobehavioral review. AIDS Rev 2009;11:103-109.

27. Arendt G, de Nocker D, von Giesen $\mathrm{HJ}$ and Nolting $T$. Neuropsychiatric side effects of efavirenz therapy. Expert Opin Drug Saf 2007; 6:147-154.

28. Friis-Møller N, Sabin CA, Weber R, d'Arminio MA, El-Sadr WM, Reiss $\mathrm{P}$, et al. Combination antiretroviral therapy and the risk of myocardial infarction. N Engl J Med 2003; 349:1993-2003.

29. Friis-Moller N, Reiss $P$, Sabin CA, Weber R, Monforte AD, El-Sadr W, et al. Class of antiretroviral drugs and the risk of myocardial infarction. N Engl J Med 2007; 356:1723-1735.

30. Fernandez-Fernandez B, Montoya-FerrerA, SanzAB, SanchezNiño MD, Izquierdo MC, Poveda J, et al. Tenofovir Nephrotoxicity 2011 update AIDS Research and Treatment Volume 2011 (2011), Article ID 354908, 11 pages.

31. Gallant JE, Winston JA, DeJesus E, Pozniak AL, Chen SS, Cheng AK, et al. The 3-year renal safety of a tenofovir disoproxil fumarate vs. a thymidine analogue-containing regimen in antiretroviral-naive patients. AIDS 2008; 22:2155-2163.

32. Mehta N. Drug-Induced Hepatotoxicity, cited (June 20th, 2015) available from http://emedicine.medscape.com/article/169814overview.

33. Hasse B, Günthard HF, Bleiber G and Krause M. "Efavirenz intoxication due to slow hepatic metabolism". Clinical Infectious Diseases 2005; 40 (3): e22-23.

34. Lowenhaupt EA, Matson K, Qureishi B, Saitoh A and Pugatch D. "Psychosis in a 12-year-old HIV-positive girl with an increased serum concentration of efavirenz". Clinical Infectious Diseases 2007; 45 (10): e128-130.

35. Cespedes MS and Aberg JA. "Neuropsychiatric complications of antiretroviral therapy." Drug safety: an international journal of medical toxicology and drug experience 2006; 29 (10): 865-874.

36. Núñez M, Lana R, Mendoza JL, Martín-Carbonero L and Soriano $V$. "Risk factors for severe hepatic injury after introduction of highly active antiretroviral therapy," Journal of Acquired Immune Deficiency Syndromes 2001;27(5): 426-431.

37. Edwards CRW, Bouchier IAD, Haslett $C$ and Chilvers EE. Diabetes Mellitus in Davidson's Principle and Practice of Medicine (10th Edition). London Churchhill Livingstone, 2008;724-774.

38. Crook MA. Clinical Biochemistry and metabolic Medicine. $8^{\mathrm{TH}}$ ed., London Edward Arnold publishers, 2012; 254-255.

39. Center for Disease Control. Prevention of neural tube defect cited (July 12th, 2015) available from http://www.cdc.gov/mmwr/ preview/mmwrhtml/00019479.htm.

40. Peter Al, Ekanem BT, Ekong MB, Oguemedom HE and Archibong AM. Ameliorative effects of Neurovite ${ }^{\mathrm{TM}}$ on 
histopathological changes of the cerebellum of lamuvidine treated Wistar rats. Journal of Neurochemistry 2013; 125(Suppl. 1):70.

41. Castelnuovo B, John L, Lutwama F, Ronald A, Spacek LA, Bates $M$, et al., "Three-year outcome data of second-line antiretroviral therapy in Ugandan adults: good virological response but high rate of toxicity." Journal of the International Association of Physicians in AIDS Care 2009; 8(1): 52-59.
42. Peter Al and Ekandem GJ. Immunohistopathological Effects of Combined Administration of Douvir-N and Folc Acid onthe Liver and Some Biochemical Parameters in Albino Wistar Rats. American Journal of BioScience 2015; 3(6):197-202.

42. Peter Al, Ekandem GJ, Igiri AO, Ekong MB and Udoh DK. Histochemical Changes in the Cerebellum of Wistar Rats Administered with Oral Doses of Zidovudine. American Journal of Bioscience and Bioengineering 2015; 3(3):17-21.

\section{Authors Contribution:}

AIP - Concept and Design of the study, Experimentation, Review of literature, Manuscript preparation and statistical analysis; IAE - Experimentation, Review of literature and Final approval of manuscript.

Source of Support: Nil, Conflict of Interest: None declared. 